

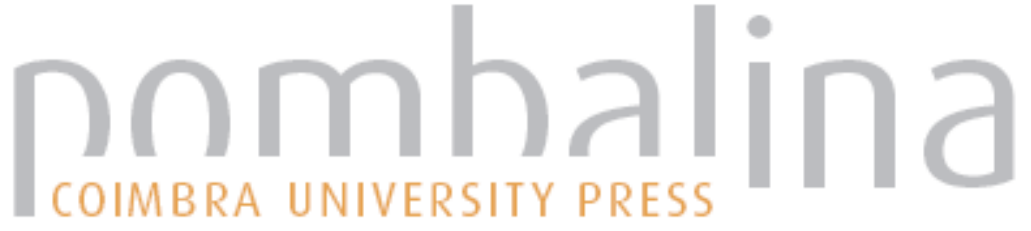

\section{Comunicação social e direitos fundamentais: um círculo virtuoso?}

\author{
Autor(es): $\quad$ Faria-Costa, José de \\ Publicado por: Imprensa da Universidade de Coimbra \\ URL \\ persistente: \\ URI:http://hdl.handle.net/10316.2/36660 \\ DOI: \\ DOI:http://dx.doi.org/10.14195/978-989-26-0873-0_21
}

Accessed : $\quad$ 26-Apr-2023 15:17:02

A navegação consulta e descarregamento dos títulos inseridos nas Bibliotecas Digitais UC Digitalis, UC Pombalina e UC Impactum, pressupõem a aceitação plena e sem reservas dos Termos e Condições de Uso destas Bibliotecas Digitais, disponíveis em https://digitalis.uc.pt/pt-pt/termos.

Conforme exposto nos referidos Termos e Condições de Uso, o descarregamento de títulos de acesso restrito requer uma licença válida de autorização devendo o utilizador aceder ao(s) documento(s) a partir de um endereço de IP da instituição detentora da supramencionada licença.

Ao utilizador é apenas permitido o descarregamento para uso pessoal, pelo que o emprego do(s) título(s) descarregado(s) para outro fim, designadamente comercial, carece de autorização do respetivo autor ou editor da obra.

Na medida em que todas as obras da UC Digitalis se encontram protegidas pelo Código do Direito de Autor e Direitos Conexos e demais legislação aplicável, toda a cópia, parcial ou total, deste documento, nos casos em que é legalmente admitida, deverá conter ou fazer-se acompanhar por este aviso. 
www.uc.pt/ imprensa_uc CONTACTO imprensa@uc.pt VENDAS ONLINE http://livrariadaimprensa.uc.pt JANEIRO 2015
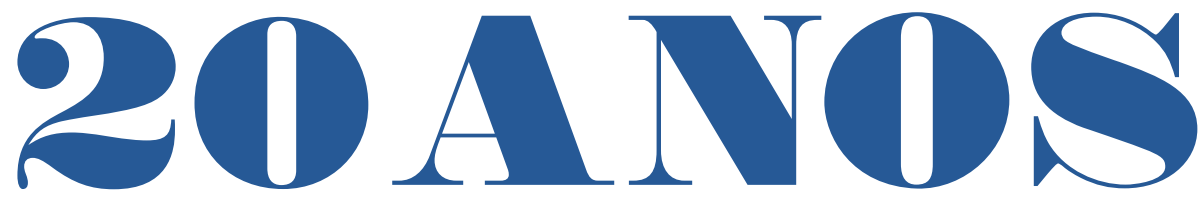

\section{DE JORNALISMO CONTRA A INDIFERENÇA}

TEXTOS DE

Marc Lits, Adriano Duarte Rodrigues, Tito Cardoso e Cunha, José Augusto Mourão, Alberto Pena Rodríguez, Maria Augusta Babo, Daniel Cronu, João Pissarra Esteves, Gilles Gauthier, Heloísa Paulo e Luís Reis Torgal, Alfredo Barroso, António Fidalgo, Nöel Nel, João de Almeida Santos, Juan Luis Cebrián, António Dias Figueiredo, Marina Themudo, Jorge Sampaio, Nelson Traquina, Mário Soares
( livro que agora se apresenta, nasce de dois desígnios fundamentais: por um lado, celebrar duas décadas de ensino do Jornalismo na Universidade de Coimbra e, por outro, partilhar com um público mais alargado um conjunto de reflexões sobre os media, o jornalismo, a comunicação e o espaço público.

Se o ensino superior do Jornalismo em Portugal, relativamente tardio em relação ao resto da Europa, deu os seus primeiros passos no fim dos anos 70 do século passado, ele aparece apenas duas décadas depois na academia coimbrã. Contudo, esta foi, no contexto nacional, a primeira licenciatura em Jornalismo, distinguindo-se, quer em título, quer em objetivos, das licenciaturas então existentes no país. A criação de uma Licenciatura em Jornalismo na Universidade de Coimbra, em 1993-1994, foi, por si, um acontecimento. Com efeito foi necessário que reitor, professores e jornalistas ousassem atualizar a oferta curricular da Faculdade de Letras, oferecendo um curso há muito desejado pela sociedade e pelo mercado, embora desconsiderado por alguns setores da academia. Correndo o risco de omitir alguém, a quem antecipadamente pedimos desculpa, não podemos deixar de recordar os esforços dos jornalistas João Mesquita, João Fonseca, em representação
Todas as gerações, sem dúvida, se julgan para refazer o mundo. A minha sabe, nc que não poderá refazê-lo. A sua tarefa é tc

Consiste em impedir que se desfaça, $p$ unicamente das suas negações A. Camus, Discursos da Suécia (1957)

do Sindicato dos Jornalistas, e de Jorge Castilho, a quem mais tarde se viria associar o nome de Mário Martins, bem como o do então Reitor da Universidade de Coimbra Rui Alarcão, e dos professores João Roque e Luís Reis Torgal. Entre 1993 e 1996, a Licenciatura em Jornalismo funcionou com um Secretariado, que teve um papel executivo e científico nos primeiros tempos do curso na FLUC. Presidido pelo Presidente do Conselho Científico Ludwig Scheidl, este 


\section{Comunicação social e Direitos Fundamentais. Um círculo virtuoso? ${ }^{1}$}

José de Faria-Costa

Provedor de Justiça

Sumário: 1. Dizeres prévios. 2. O cidadão, a comunidade e os direitos fundamentais 3. A relação dialéctica que se estabelece entre a comunicação social e os direitos fundamentais: o papel da comunicação social na promoção e defesa dos direitos humanos. Potencialidades e fragilidades. 4. Dizeres conclusivos.

\section{Dizeres prévios}

O nosso tempo do qual não podemos fugir porque somos seres imorredoiramente ligados ao devir histórico é marcado por riscos, paradoxos e perturbação social, que se manifestam, cada vez mais e de um jeito mais forte, na hipercomplexidade das relações sociais que se estabelecem entre os cidadãos, a comunidade e o próprio Estado.

Não queremos com isto dizer, fique bem claro, que a desesperança ou o pessimismo que se possa sentir no panorama hodierno estrangulem a nossa capacidade de agir no presente e de ter um horizonte de futuro. Apenas o afirmamos em este primeiríssimo momento porquanto, só aceitando como natural esta circunstância, poderemos escapar à resignação que paralisa o pensamento e a acção.

A mutação rápida e constante das relações sociais tem sido acompanhada e, em um certo sentido, influenciada pela evolução de igual sinal na comunicação social, seja no domínio tecnológico, seja no modus como se estruturam os meios formais e informais de divulgação de informação.

É hoje evidente para todos que a facilidade do acesso à informação, quer seja mediada pelos órgãos de comunicação social - se bem que nem sempre pelo jornalista - quer advenha do contacto directo que o cidadão estabelece

\footnotetext{
${ }^{1}$ Esta brevíssima conferência teve a colaboração do Dr. Ricardo Carvalho, Adjunto do meu Gabinete, e foi proferida na Faculdade de Letras da Universidade de Coimbra, no dia 31 de Outubro de 2014, no âmbito das comemorações do XX aniversário da Licenciatura em Jornalismo. Este texto não foi redigido de acordo com o chamado novo acordo ortográfico.
} 
com as mais variadas fontes informais, altera permanentemente o núcleo fundante da relação matricial estabelecida entre o "eu" e o "outro", a comunidade e o próprio Estado.

A pulverização dos meios de comunicação social, associada à evolução tecnológica e à procura incessante e insaciável de informação por parte do cidadão, tem um impacto directo e relevante na representação simbólica que o mesmo cidadão faz das instituições da comunidade. E isso não pode deixar de nos convocar não apenas enquanto cidadãos individuais - com responsabilidades de actuação na microesfera do quotidiano - mas também enquanto cidadãos que, inseridos em uma comunidade, têm para com ela o especial dever de contribuir de forma activa para a defesa de um dos seus alicerces fundacionais, como são os direitos fundamentais.

\section{O cidadão, a comunidade e os direitos fundamentais}

Em uma sociedade democrática o reconhecimento do valor intrínseco dos direitos fundamentais dos cidadãos, sustentado no baluarte da defesa da dignidade da pessoa humana, constitui um pilar essencial da afirmação do Estado. Reconhecimento que se cristaliza em normas do texto fundamental e que desenha em termos muito concretos as bases sobre as quais se estabelecem as relações dos cidadãos entre si e de estes com o próprio Estado. Este elo que une os cidadãos ao Estado determina um sentimento de pertença e fortifica a relação de confiança sobre a qual toda a comunidade se edifica.

Apesar disso, o catálogo constitucional não é um repositório hermético dos direitos fundamentais. Estes têm uma existência e uma força que extravasam as muralhas do texto fundamental. Estas particularidades são expressamente reconhecidas pela nossa Constituição na medida em que ela própria assume uma vocação universalista. Dito de um outro jeito: é a própria Constituição que reconhece outros direitos fundamentais fora do catálogo e, até mesmo, fora da dimensão normativo-constitucional.

É de assinalar que, todos o sabemos, quando falamos de direitos fundamentais englobamos no seu seio a protecção do multiversum pluridimensional do ser humano: do ser na sua mais ínfima manifestação de singularidade (v.g. o direito à vida que é expressão máxima da protecção daquilo que é único em cada um de nós) mas também do ser comunitariamente inserido (v.g. direito à saúde, direito à habitação).

Os direitos fundamentais que brotam deste multiversum pluridimensional ele próprio com densificações axiológicas distintas - manifestam graus de 
protecção também eles diferenciados. Se é certo que a tutela dos direitos, liberdades e garantias se expressa no cumprimento estadual de um dever geral de abstenção, para usarmos uma categoria dogmática em que se estriba o nosso ordenamento jurídico, também é verdade que a densificação constitucional dos chamados direitos económicos, sociais e culturais é mais lassa atenta a natureza prestacional que estes direitos reclamam da actuação do Estado.

\section{A relação dialéctica que se estabelece entre a comunicação social e os direitos fundamentais: o papel da comunicação social na pro- moção e defesa dos direitos humanos. Potencialidades e fragilidades}

Afirmámos que a facilidade no acesso à informação é uma das características deste nosso tempo. Também já o dissemos que a procura e a oferta de informação, pela voracidade que as caracteriza, têm implicações fundas nas representações sociais e na relação entre os cidadãos e o Estado.

É certo que a progressiva afirmação e reconhecimento dos direitos fundamentais estão intimamente relacionados com a apreensão pelo próprio cidadão da sua dimensão de Sujeito de Direito. E este percurso é influenciado, algumas vezes, pelo papel interventor dos meios de comunicação social que, ao relatarem situações do quotidiano que tocam os direitos fundamentais ou algumas das suas manifestações, trazem-nos para o palco da vida comunitária. E esse foco luminoso que teimosamente incide sobre as dimensões individual e comunitária do ser pessoa, potencia o escrutínio público da actuação dos órgãos do Estado ou da actuação daqueles que exercem poderes públicos.

Por esta fundamental particularidade têm os órgãos de comunicação social um especial dever de, sem beliscar a liberdade de imprensa - ela mesma um direito fundamental -, contribuir de modo responsável, sério e rigoroso para a consciencialização colectiva pelo respeito dos direitos fundamentais. Este é um papel importantíssimo em uma sociedade democrática que cabe aos órgãos de comunicação social, manifestando um verdadeiro exercício de cidadania.

Por isso a Constituição da República Portuguesa estabelece no artigo $38 .^{\circ}$ não apenas o direito à liberdade de imprensa do qual decorrem, entre outros direitos, o da liberdade de expressão do jornalista, o livre acesso às fontes, e o respeito pela imparcialidade e independência do jornalista - mas também um amplo elenco de garantias que respeitam à organização interna dos meios de comunicação social e ao particular papel que a estes compete em 
uma sociedade plural e democrática. Só um valor forte pode justificar a opção do nosso legislador constitucional quando, sobre esta matéria, determina as regras essenciais que devem reger a actividade jornalística, sobretudo quando essas regras ultrapassam largamente a estrita esfera da actividade individual do jornalista. Falamos da obrigação que o próprio Estado assume como sua em assegurar a liberdade e a independência dos órgãos de comunicação social perante o poder político e o poder económico ${ }^{2}$ e, ao mesmo tempo, de impedir a concentração dos órgãos de comunicação social, designadamente por via de participações sociais múltiplas ou cruzadas. Se é certo que a exigência de liberdade e independência dos órgãos de comunicação social face ao poder político é uma circunstância que decorre naturalmente das regras mínimas da afirmação e vivificação da democracia, já a imposição dessa mesma liberdade e independência face ao poder económico e o impedimento de concentração de empresas de comunicação, espelham, e bem, afirmemo-lo sem pudor, a relevância e o manifesto interesse público de que se reveste o exercício da actividade dos media e que justifica as limitações à iniciativa privada.

Deste jeito, revelam-se perante nós, e em toda a sua plenitude, as razões fundantes da particular atenção que o nosso ordenamento jurídico concede à organização e funcionamento dos órgãos de comunicação social e ao exercício da actividade jornalística.

Todavia, digamo-lo abertamente e com total limpidez, nem sempre o tratamento que é dado às situações do quotidiano e que colocam em crise os direitos fundamentais, têm da parte dos órgãos de comunicação social uma atenção cuidada. Todos já tivemos em algum momento oportunidade de o vivenciar. E isto nada tem que ver com uma menor consideração ou apoucamento do trabalho que é desenvolvido pelas senhoras e senhores jornalistas. Na verdade hoje assistimos à pulverização da informação e à volatilidade com que a mesma é transmitida. O tempo jornalístico é um tempo mais breve do que o nosso tempo, o que condiciona, por vezes, a maturação que o relato daquele pedaço de realidade exige. A tudo isto acresce a primazia que hoje é dada à informação em tempo real, que veio reconfigurar os próprios órgãos de comunicação social, e para a qual, paradoxalmente, o próprio cidadão activamente contribui.

O frémito noticioso que a todos nós envolve leva-nos a procurar incessantemente a última notícia ou a última novidade revelada pela notícia. Hoje não nos conforta aguardar pela chegada do jornal ao quiosque da nossa rua;

${ }^{2}$ Cfr. n. ${ }^{\circ} 4$ do art. $38^{\circ}$ da Constituição da República Portuguesa. 
já não é bastante chegarmos a casa, depois de um intenso dia de trabalho, para assistirmos às notícias; ou esperarmos pela hora certa para as escutar na rádio. Temos à distância de um simples dedilhar - no tablet ou no smartphonea satisfação da pulsão noticiosa.

Ora, esta realidade põe um problema novo. Qual o sentido e valor que devemos atribuir ao papel que cada um de nós desempenha na teia comunicacional que os tempos de hoje constroem? Seremos, nós, simples receptores passivos da informação que a nossa razão crítica joeira? Julgamos que as coisas se alteraram profundamente. Radicalmente. Temos para nós que, hoje, fazemos parte do fluxo informacional e não somos só pólos da relação comunicacional. Por outras palavras: fazemos parte indestrutível da própria informação. Mais. Somos instrumentos ao serviço do fluxo informacional. Enquanto na visão clássica o acesso à informação era um bem, um valor que "eu", como último e irredutível valor final, usava, e nesse sentido instrumentalizava, agora, o "eu" que procura a informação é ele próprio parte intrínseca dessa informação. Desaparecendo por completo a distinção, neste campo, entre valor final e valor instrumental. Basta um exemplo comezinho para ilustrar o que dizemos. Na verdade, para se informar sobre uma qualquer tendência, independentemente da matéria em que nos situemos, o que fazem os meios actuais de informação de massa digitais? Perguntam a nossa opinião, através de inquéritos, cuja validade ou bondade se desconhece em absoluto. Isto é: a informação que mais tarde vamos colher é em parte já nossa. Fomos instrumentalizados para que se pudesse chegar àquele resultado informacional. Com a vertigem de tudo querer reduzir a dados e a estatísticas não nos apercebemos que também aqui fomos perdendo autonomia para ganharmos um pseudo aumento de conhecimento que, ao cabo e ao resto, pouco ou nada acrescenta ao nosso enriquecimento interior ou mesmo à nossa autonomia informacional. E se passarmos para o domínio do divertimento televisivo vemos, através do engodo de que é o telespectador que decide, não só pessoas a exporem da maneira mais descarada a sua mais profunda intimidade (v. g. os chamados reality shows), como nos damos conta de pseudoparticipações opacas em que se promove, às vezes de forma intolerável, a chamada de valor acrescentado. Estas são ilustrações que mostram, de forma dolorosa, como se fundiram, em total indiferenciação, os valores finais e os valores instrumentais que a relação ôntica entre comunicação e informação evidenciava.

A evolução avassaladora e permanente dos meios tecnológicos tem contribuído de um modo determinante e decisivo para estas mudanças de 
comportamento dos cidadãos, tornando-os, por um lado, mais interessados e participativos, e, por outro, paradoxalmente, mais expostos à simplificação e vulgarização das situações que contendam com os seus direitos fundamentais. E esta simplificação e vulgarização é, reconheçamo-lo, fonte de vulnerabilidade.

Vulnerabilidade, desde logo do cidadão, principalmente daquele que em virtude das circunstâncias da sua vida está mais desprotegido e exposto a riscos acrescidos de exclusão e, por essa razão, tolhido de meios de defesa face às situações que contendem com os seus direitos fundamentais, designadamente daqueles que protegem a sua privacidade e intimidade.

Mas essa vulnerabilidade não põe em crise apenas a esfera individual do cidadão, espraia-se pela comunidade. Na verdade, a simplificação do que é por natureza complexo traduz-se, não raras vezes, na ínfima expressão de um sound bite que, por esconder a verdadeira dimensão da situação, não permite que o cidadão se aperceba das subtilezas e enredos que toda a realidade encerra. E isso fragiliza a comunidade no preciso ponto em que subtrai ou limita a discussão dos problemas e desafios da nossa polis em uma base sustentada no conhecimento.

É desta dimensão da actividade jornalística a do conhecimento - que resulta emana a responsabilidade do jornalista para com a comunidade e para com os cidadãos. Responsabilidade que se revela em a sua mais alta expressão na exigência, também jurídica, de o jornalista pautar o exercício da sua actividade por elevados padrões éticos espelhados na busca incessante da verdade e do respeito pelo outro, sem desvios ou transigências, e imune à tentação, sempre presente, da simplificação e vulgarização do real.

\section{Dizeres conclusivos}

As últimas duas décadas são marcadas por alterações profundíssimas no panorama da comunicação social, quer no tocante à discussão da problemática da propriedade dos meios de comunicação social, à emergência de novas formas de estabelecimento das relações profissionais entre os jornalistas e as empresas proprietárias dos meios de comunicação, quer no tocante às novas formas de difusão da informação.

Sublinhe-se, a traço firme, que esta nova dimensão tecnológica, em si mesma, nada tem de mal. Não engrossamos as fileiras de todos aqueles que vêem na evolução tecnológica a desagregação comunitária. Bem pelo contrário. É em virtude dessa mesma evolução que a humanidade tem hoje ao seu dispor uma panóplia de ferramentas que, cumprindo a sua finalidade instru- 
mental, permitem alcançar patamares superiores de respeito pelos direitos fundamentais.

Não obstante vivermos em um tempo no qual todas as aquisições científicas e tecnológicas no domínio da comunicação potenciam em abstracto o aprofundamento da participação do cidadão na vida da comunidade - o que se constitui como factor de progresso - também não é menos verdade que essas aquisições moram paredes meias com o risco de restringir o que existe àquilo que se informa.

Para terminar podemos e devemos enviar uma mensagem de esperança. Esperança de que o melhor jornalismo seja, como tem sido, uma importante força motriz na construção de uma sociedade. Esperança de que o melhor jornalismo aprofunde a democracia pela amplificação da dimensão participativa do cidadão na vida da sua comunidade. Esperança de que o melhor jornalismo, porque fiel ao valor supremo da verdade, valha ou seja esta o que seja, contribua para a construção de uma cultura de respeito pelos direitos fundamentais dos cidadãos. Por fim, esperança, coberta de comprometimento ético, de que o melhor jornalismo, independentemente das plataformas onde se realize, assuma a regra de ouro de que o "outro", mesmo quando é notícia pelas piores razões, não deixa de ser um sujeito de direitos, não passa, pois, a mero objecto, e, por consequência, merecedor, ainda e sempre, de respeito. 